\title{
GÊNESE E EVOLUÇÃO DAS TEMPERATURAS MÍNIMAS ABSOLUTAS NA REGIÃO CENTRO-SUL DO PARANÁ: A INFLUÊNCIA DA DINÂMICA ATMOSFÉRICA E DO RELEVO LOCAL
}

\author{
GENESIS AND EVOLUTION OF ABSOLUTE MINIMUM TEMPERATURES IN \\ THE CENTRALSOUTHERN REGION OF PARANÁ STATE: INFLUENCE OF \\ ATMOSPHERIC DYNAMICS AND LOCAL RELIEF
}
GÉNESIS Y EVOLUCIÓN DE LAS TEMPERATURAS MÍNIMAS ABSOLUTAS EN LA REGIÓN CENTRO-SUR DE PARANÁ: LA INFLUENCIA DE LA DINÁMICA ATMOSFERICA Y EL RELIEVE LOCAL
Claudiane da Costa - Universidade Estadual do Centro-Oeste - Guarapuava - Paraná - Brasil
clau_dianecosta@hotmail.com

\begin{abstract}
Aparecido Ribeiro de Andrade - Universidade Estadual do Centro-Oeste - Guarapuava - Paraná - Brasil apaandrade@gmail.com
\end{abstract}

\section{Resumo}

Este trabalho analisou a variabilidade das temperaturas mínimas absolutas, associada ao desenvolvimento de sistemas atmosféricos na região Centro-Sul do Paraná. Foram selecionados os municípios de Guarapuava, Palmas e Irati para representar a área, tanto pela localização, quanto pela base de dados disponível. Foram avaliados dados de temperatura diária, cedidos pelo IAPAR (Instituto Agronômico do Paraná) e INMET (Instituto Nacional de Meteorologia) e de imagens de satélite, cedidas pelo SIMEPAR (Instituto Tecnológico do Paraná), referentes aos invernos de 2004 a 2012. Os dados de temperatura foram tabulados no software Microsoft Office Excel ${ }^{\circledR}$ e as imagens de satélite analisadas por meio de vídeos produzidos no Windows Live $^{\mathrm{TM} M o v i e M a k e r}{ }^{\circledR}$. Ocorre maior influência das massas de ar Polares ( $\mathrm{mPa}$ e mPp), mas a Massa Tropical Continental atuou frequentemente no período analisado, atenuando o resfriamento superficial em vários dias. Palavras-chave: massas de ar, temperaturas negativas, climatologia geográfica.

\section{Abstract}

This study analyzed the frequency and intensity of absolute minimum temperatures associated with atmospheric systems in the Central Southern Paraná State. It was selected the municipalities of Guarapuava, Palmas, and Irati to represent the area, both considering the location and the available database. Daily temperature data provided by Agronomic Institute of Paraná (IAPAR) and National Meteorological Institute (INMET) and satellite imagery provided by Technological Institute of Paraná (SIMEPAR) were analyzed in the winter seasons from 2004 to 2012. Data of temperature were tabulated in Microsoft Excel and satellite imagery was analyzed through videos produced in Windows Live ${ }^{\mathrm{TM}}$ Movie Maker ${ }^{\circledR}$. The highest influence of polar air masses ( $\mathrm{mPa}$ and $\mathrm{mPp}$ ) was prevalent, but the continental tropical mass frequently affected the study period, by reducing the surface cooling for several days.

Keywords: air masses, negative temperatures, geographical climatology. 
Resumen

Este trabajo analizó la variabilidad de las temperaturas mínimas absolutas, asociadas al desarrollo de sistemas atmosféricos en la región Centro-Sur de Paraná. Fueron seleccionados los municipios de Guarapuava, Palmas e Irati para representar la región, tanto por su localización, cuanto por su base de datos disponibles. Fueron evaluados datos de temperatura diaria, cedidos por IAPAR (Instituto Agronómico de Paraná) e INMET (Instituto Nacional de Meteorología) e imágenes satelitales, cedidas por SIMEPAR (Instituto Tecnológico de Paraná), referentes a los inviernos de 2004 a 2012. Los datos de temperatura fueron tabulados en el software Microsoft Office Exce/ ${ }^{\circledR}$ y las imágenes satelitales analizadas a través de videos producidos en el Windows LiveTMMovieMaker ${ }^{\circledR}$. Ocurre mayor influencia de las masas de aire Polares (mPa y mPp), pero la Masa Tropical Continental que actuó frecuentemente en el período analizado, atenuando el enfriamiento superficial en varios días.

Palabras clave: masas de aire, temperaturas negativas, climatología geográfica.

Introdução

A Climatologia e a Meteorologia amparam suas bases analíticas em dados diários das condições do tempo. Dentre esses dados, a maior ou a menor temperatura do ar, observadas no decorrer do dia, são conhecidas como máxima e mínima. Normalmente, em se tratando de um período de 24 horas, tem-se apenas uma temperatura máxima e outra mínima. Entretanto, em períodos maiores, as expressões "máximas absolutas e mínimas absolutas” são mais acertadas, por definirem a maior máxima e a menor mínima para um intervalo de tempo qualquer (Varejão-Silva, 2001).

A partir de 1960 a meteorologia teve um grande avanço com o surgimento de satélites que possibilitaram a visualização e o acompanhamento da evolução de sistemas meteorológicos. Essa técnica melhorou substancialmente as interpretações das condições do tempo, apesar das imagens não identificarem, necessariamente, as massas de ar e as frentes frias, mas apenas auxiliarem na sua visualização. Portanto, os dados de superfície devem sempre ser considerados na identificação de uma massa de ar e nos efeitos que ela causa. Esse é o tema central discutido nesse trabalho e que busca definir, mesmo que de forma empírica, a atuação dos sistemas atmosféricos na região Centro-Sul do Paraná.

A região Sul do Paraná e a região Sul do Brasil como um todo, se destacam pelo seu inverno rigoroso em relação a outras regiões do país. Essa área apresenta temperaturas mínimas significantes no período de inverno (junho, julho e agosto), com geadas frequentes, podendo até ocorrer precipitação de neve em alguns locais.

Durante os meses de inverno, a variabilidade termal no Sul e Centro-Sul do Paraná é associada principalmente à evolução da Massa 
Polar Atlântica - mPa, que aliada à altitude de algumas localidades, pode provocar quedas significativas na temperatura do ar, resultando em um frio mais intenso do que em outras regiões do estado. Ocorrem situações em que a Massa Polar Pacífica (mPp) também influencia as temperaturas do Sul do Brasil. Isso é comum quando essa massa ultrapassa a Cordilheira dos Andes e entra no interior do continente sul-americano, mais especificamente na Argentina, no Paraguai e no Brasil (Costa, 2013).

As massas de ar podem ser definidas como um grande corpo de ar horizontal e homogêneo que se desloca como uma entidade reconhecível, podendo ser tropical ou polar, modificando-se conforme sua evolução. Sua origem ocorre em áreas onde existem condições que favorecem o desenvolvimento de vastos corpos de ar horizontais e uniformes. O estado do Paraná sofre influências das massas de ar Polar Atlântica (mPa), Tropical Atlântica (mTa) e Tropical Continental (mTc) (Ayoade, 1986).

Além desses sistemas, a Massa Equatorial Continental (mEc) também é importante na variabilidade das condições de tempo no Paraná. Contudo, isso só ocorre no verão e na porção noroeste do estado, o que justifica o fato desse trabalho não abordar sua dinâmica e nem considerá-la nas avaliações dos resultados.

Portanto, o presente estudo considerou todos os sistemas atuantes na região (mPa; $\mathrm{mPp}$; mTc e mTa) durante o inverno local e não somente a $\mathrm{mPa}$, reconhecidamente a mais importante nas quedas de temperatura para a área de estudo. Mesmo que a mTc e a mTa não atuem de forma significativa, nessa estação do ano, elas podem produzir bloqueios, evitando quedas mais acentuadas nas temperaturas, principalmente nas áreas mais ao norte e noroeste.

Essa dinâmica climática define temperaturas mínimas bem acentuadas para a região Sul do Paraná. Tal fato foi comprovado por Caviglione et al. (2000), ao demonstrarem que as temperaturas mínimas na parte sul e centro-sul paranaense são as mais baixas do estado, oscilando, em média, entre 11 e $13^{\circ} \mathrm{C}$ no mês mais frio. Entretanto, deve-se ressaltar que esses são valores médios, normalmente as temperaturas mínimas absolutas são bem inferiores.

Essa afirmação vai ao encontro do estudo feito por Thomaz e Vestena (2003), em que afirmam ser extremamente comum ocorrerem geadas ao amanhecer, com temperaturas próximas ou abaixo de zero, em vários dias do inverno sul paranaense. 
Os dados meteorológicos utilizados para o presente estudo foram coletados diariamente e os instrumentos de coleta estavam localizados entre as regiões Centro-Sul e Sul do Estado do Paraná (Quadro 1), nos municípios de Guarapuava, Irati e Palmas. Essas localidades foram selecionadas em virtude de apresentarem temperaturas bem mais baixas durante o período do inverno (junho, julho e agosto) em relação a outros locais do estado. Todas elas têm altitude próxima a 1000m e estão na transição do segundo para o terceiro planalto paranaense, tendo suas dinâmicas climáticas influenciadas pelo controle climático denominado de Escarpa da Serra da Esperança.

É conveniente enfatizar que o período selecionado para análise (2004 a 2012) foi definido a partir dos dados disponíveis e consistentes para todos os municípios. Os dados anteriores a 2004 continham muitas falhas e, além disso, as imagens de satélite do SIMEPAR (Instituto Tecnológico do Paraná) só foram disponibilizadas desse ano em diante. Associada a essa questão, teve o fato de que uma análise temporal mais ampla demandaria recursos que atualmente os autores não dispõem.

Quadro 01 - Aspectos Geográficos dos municípios selecionados para análise

\begin{tabular}{|c|c|c|c|}
\hline Categorias & \multicolumn{3}{|c|}{ Municípios } \\
\hline & Guarapuava & Palmas & Irati \\
\hline Altitude & 1.098 Metros & 1.035 Metros & 820 Metros \\
\hline Latitude & $25^{\circ} 23^{\prime} 26^{\prime \prime} \mathrm{S}$ & $26^{\circ} 29^{\prime} 03^{\prime \prime} \mathrm{S}$ & $25^{\circ} 28^{\prime} 02^{\prime \prime} \mathrm{S}$ \\
\hline Longitude & $51^{\circ} 59^{\prime} 15^{\prime \prime} \mathrm{W}$ & $51^{\circ} 59^{\prime} 26^{\prime \prime} \mathrm{W}$ & $50^{\circ} 39^{\prime} 04^{\prime \prime} \mathrm{W}$ \\
\hline Classificação Climática & Subtropical Úmido & Clima Temperado Úmido & Clima Temperado \\
\hline
\end{tabular}

Fonte: IBGE e IPARDES (2013). Organização: Costa e Andrade (2014).

O objetivo deste trabalho foi identificar os sistemas atuantes através de imagens de satélite, mas foram os registros de superfície que definiram a efetiva ação desses sistemas. Em uma área como a desse estudo (Figura 01), localizada na região Centro-Sul do Paraná, numa porção considerada subtropical (latitudes inferiores a $23^{\circ} 30^{\prime} \mathrm{S}$ ), com temperaturas de inverno muito baixas, esse é um tema bem instigante.

Dessa forma, para atender aos objetivos propostos, foram selecionados os três municípios com registros históricos mais consistentes, procedimento realizado com base na análise de banco de dados fornecido 
pelo Instituto Agronômico do Paraná (IAPAR) e pelo INMET (Instituto Nacional de Meteorologia).

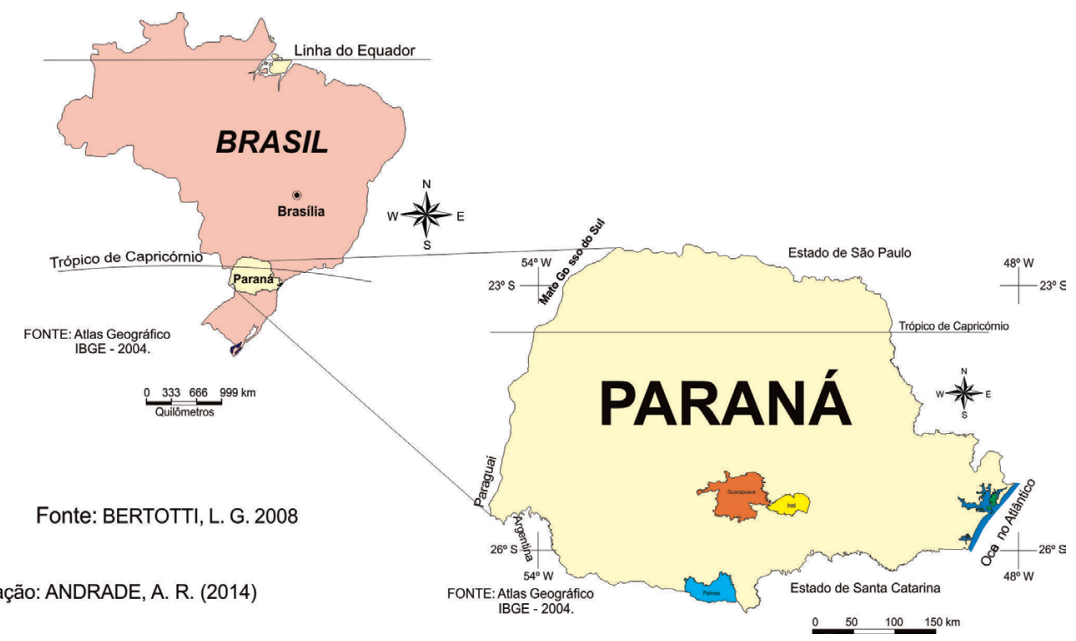

Figura 1 - Localização geográfica da região estudada (Guarapuava, Irati e Palmas) Fonte: IBGE, 2004. Elaboração: Andrade (2014).

Procedimentos Metodológicos

Para obtenção de informações confiáveis, para as análises necessárias, foi escolhido um método qualitativo de organização dos dados disponíveis. Dessa forma, em um primeiro momento, foi realizada a tabulação dos dados das temperaturas mínimas diárias no período do inverno de 2004 ao inverno de 2012 para os municípios estudados. Esses dados foram obtidos junto ao IAPAR e ao INMET.

Depois que as temperaturas mínimas absolutas foram avaliadas, elas foram comparadas conforme as informações constantes no Quadro 2. Convém ressaltar que a seleção dos dias obedeceu a critérios estritamente comparativos, ou seja, houve vários outros dias em que as temperaturas mínimas absolutas estiveram negativas, mas foram selecionados somente aqueles em que pelo um dos municípios obteve temperatura positiva. Esses procedimentos foram realizados no software Microsoft Office Excel@. 
Em seguida, foram obtidas junto ao SIMEPAR, as imagens de satélite dos dias escolhidos, buscando associar a ocorrência de períodos com temperaturas mínimas severas à dinâmica atmosférica local e regional. Depois de algumas tentativas, as imagens foram organizadas em vídeos, utlizando o Software MovieMaker, pois foi o procedimento que melhor possibilitou a identificação da formação e evolução das massas de ar.

Após as análises dos vídeos, foi possível identificar os sistemas atuantes em cada um dos dias. Para tanto, foram agrupadas imagens de dois dias antes e dois dias depois do evento selecionado. Dessa forma, consegue-se visualizar a trajetória das massas de ar no decorrer do período.

\section{Resultados e Discussões}

De acordo com Thomaz e Vestena (2003), as geadas na região Centro-Sul do Paraná têm sua origem decorrente da entrada de uma massa de ar fria. Na maioria das vezes, as geadas podem causar danos consideráveis, principalmente para a agricultura, dependendo de qual seja sua intensidade. Na região de estudo existe uma forte relação desses eventos com a agricultura, provocando danos que podem alcançar níveis muito altos, prejudicando o desenvolvimento social e econômico. Nesse sentido, o estudo da gênese e atuação de temperaturas mínimas absolutas é importante para um melhor entendimento da dinâmica climática destes municípios (Guarapuava, Irati e Palmas).

Quadro 02 - Dias selecionados para análise e temperaturas mínimas absolutas ${ }^{1}$

\begin{tabular}{|c|c|c|c|c|c|c|c|}
\hline Data & Guarapuava & Palmas & Irati & Data & Guarapuava & Palmas & Irati \\
\hline $14 / 06 / 2004$ & 4,2 & 2,2 & $-2,4$ & $01 / 07 / 2009$ & 2,8 & $-1,2$ & 3,3 \\
\hline $31 / 07 / 2004$ & 3,4 & $-0,8$ & 1,8 & $24 / 07 / 2009$ & 1,6 & $-2,0$ & 0,8 \\
\hline $09 / 08 / 2004$ & 2,6 & 2,0 & $-2,8$ & $25 / 07 / 2009$ & 0,4 & $-4,6$ & 3,6 \\
\hline $07 / 07 / 2005$ & 2,4 & 0,0 & $-1,4$ & $06 / 06 / 2010$ & $-1,0$ & 3,0 & 1,4 \\
\hline $31 / 07 / 2006$ & 1,4 & $-0,8$ & 3,6 & $07 / 06 / 2010$ & 0,6 & 2,6 & 2,5 \\
\hline $20 / 08 / 2006$ & 1,0 & $-0,4$ & 3,5 & $15 / 07 / 2010$ & 4,0 & $-0,4$ & 2,0 \\
\hline $22 / 08 / 2006$ & 2,0 & $-0,4$ & $-1,3$ & $15 / 08 / 2010$ & 1,8 & $-0,6$ & $-0,9$ \\
\hline $05 / 06 / 2007$ & $-0,8$ & 1,4 & 1,2 & $05 / 06 / 2011$ & 3,4 & 0,0 & $-1,6$ \\
\hline $30 / 06 / 2007$ & $-0,8$ & $-0,8$ & 1,8 & $11 / 06 / 2011$ & 4,0 & 2,4 & $-1,6$ \\
\hline
\end{tabular}




\begin{tabular}{|c|c|c|c|c|c|c|c|}
\hline Data & Guarapuava & Palmas & Irati & Data & Guarapuava & Palmas & Irati \\
\hline $01 / 07 / 2007$ & $-0,4$ & $-1,4$ & 2,4 & $05 / 07 / 2011$ & 1,2 & $-0,2$ & 0,0 \\
\hline $24 / 07 / 2007$ & 2,0 & 0,0 & 2,8 & $06 / 07 / 2011$ & 3,2 & 0,0 & 3,3 \\
\hline $28 / 07 / 2007$ & 1,2 & 2,4 & $-0,2$ & $07 / 07 / 2011$ & $-0,4$ & $-2,0$ & 1,4 \\
\hline $29 / 07 / 2007$ & 2,8 & $-0,6$ & 2,6 & $09 / 07 / 2011$ & 3,2 & 4,4 & 0,0 \\
\hline $08 / 08 / 2007$ & 4,4 & $-0,2$ & 3 & $08 / 07 / 2012$ & 2,0 & $-0,6$ & 3,1 \\
\hline $28 / 08 / 2007$ & 5,8 & $-0,8$ & 5,7 & $14 / 07 / 2012$ & $-0,2$ & $-0,6$ & 1,7 \\
\hline $10 / 06 / 2008$ & 2,2 & 0,2 & 3,9 & $15 / 07 / 2012$ & $-0,2$ & 1,6 & 2,2 \\
\hline $04 / 06 / 2009$ & 1,0 & 2,0 & $-2,1$ & $20 / 07 / 2012$ & $-0,6$ & 2,2 & 1,8 \\
\hline $06 / 06 / 2009$ & $-0,8$ & $-0,8$ & 3,4 & & & & \\
\hline
\end{tabular}

Fonte: Dados cedidos pelo INMET (2013) e IAPAR (2014).

Organização: os autores, 2014.

No total, foram selecionados 35 eventos considerados significativos para o período de estudo (2004 a 2012), conforme apresentado no Quadro 2. Esses eventos foram analisados separadamente, ressaltando a gênese e a evolução para cada um deles. Dessa forma, no dia 14 de junho de 2004, Guarapuava teve temperatura de $4,2^{\circ} \mathrm{C}$, Palmas $2,2^{\circ} \mathrm{C}$ e Irati $-2,4^{\circ} \mathrm{C}$. Nesse caso, a massa de ar que se deslocou no dia 13/06 foi a Massa Polar Atlântica - $\mathrm{mPa}$, que atuou mais intensamente no setor Leste, justificando o padrão das temperaturas do dia 14/06, quando chega enfraquecida. Mesmo assim, aliada a fatores locais (relevo e altitude), influencia na queda da temperatura em Irati.

No dia 31/07/2004 (Figuras 2a, 2b, 2c e 2d), a temperatura de Guarapuava foi de $3,4^{\circ} \mathrm{C}$, Palmas $-0,8^{\circ} \mathrm{C}$ e Irati $1,8^{\circ} \mathrm{C}$. No dia $30 / 07$ o Paraná esteve sobre influência da Massa Tropical Continental - mTc, exercendo um bloqueio em níveis médios, que se dissipa ao longo do dia. Contudo, a frente da mPa já estava atuando na região.

Por fim, no dia 31/07 avança uma nova $\mathrm{mPa}$, cujo processo frontogenético auxilia na queda de temperaturas, principalmente em Palmas, por estar mais ao Sul, onde o bloqueio da mTc não foi tão atuante.

No dia 09/08/2004, Guarapuava teve temperatura mínima de $2,6^{\circ} \mathrm{C}$; Palmas $2,0^{\circ} \mathrm{C}$ e Irati $-2,8^{\circ} \mathrm{C}$. Nesse dia, ocorreu a atuação de uma mPa vinda de leste, o que provoca a queda significativa das temperaturas em Irati, mas não ultrapassa a orografia local e, portanto, não chega aos outros municípios. 
(a) 30/07 às 01h09 (GMT-3)

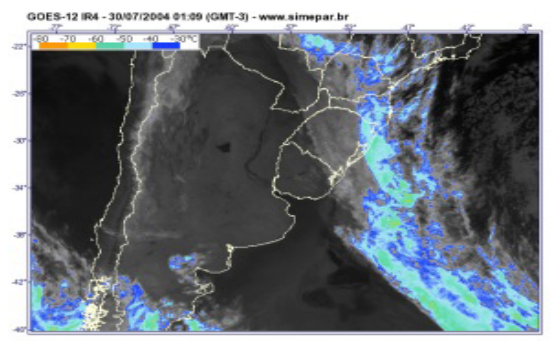

(c) $31 / 07$ às 06 h29 (GMT-3)

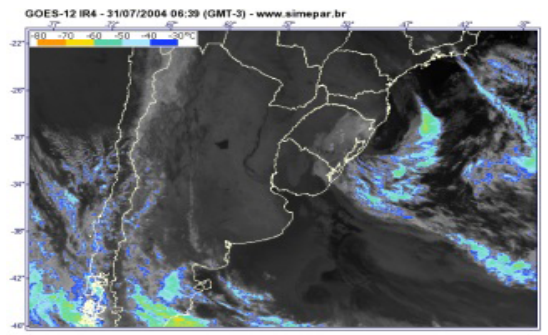

(b) 30/07 às $20 \mathrm{~h} 45$ (GMT-3)

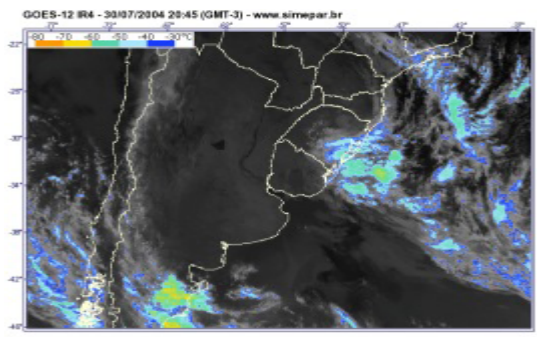

(d) $31 / 07$ às $17 \mathrm{~h} 45$ (GMT-3)

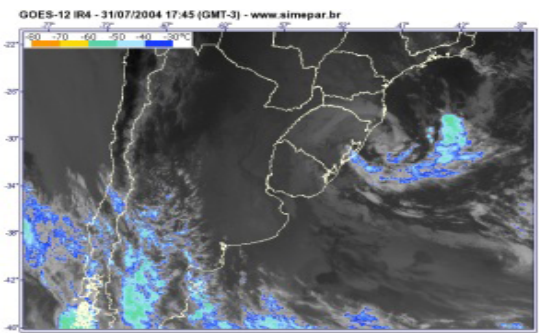

Figura 2 - Imagens Orbitais do Satélite GOES-12 (30 e 31 de julho de 2004) Fonte: SIMEPAR (Instituto Tecnológico do Paraná).

Em 2005, somente em 07/07 foi que Guarapuava apresentou temperatura mínima de $2,4^{\circ} \mathrm{C}$; Palmas $0,0^{\circ} \mathrm{C}$; e Irati $-1,4^{\circ} \mathrm{C}$ (Figura $3 \mathrm{a}, 3 \mathrm{~b}, 3 \mathrm{c}$ e 3d). Nessa ocasião os municípios de Palmas e Irati tiveram temperaturas baixas com influência da $\mathrm{mPa}$, tanto no ramo sudoeste, quanto leste. Portanto, sua evolução ocorreu ao longo do dia e acabou se dissipando, chegando mais enfraquecida em Guarapuava.

No dia 31/07/2006, Guarapuava apresentou temperatura mínima de $1,4^{\circ} \mathrm{C}$, Palmas de $-0,8^{\circ} \mathrm{C}$ e Irati $3,6^{\circ} \mathrm{C}$. Guarapuava e Palmas tiveram temperaturas mais baixas, explicadas pela ação da Massa Polar Pacífica - mPp, mas foi principalmente em Palmas que essa dinâmica foi mais intensa. Já em Guarapuava e Irati esse efeito foi menor, em virtude da atuação da mTc, provocando um bloqueio. 
(a) 06/07 às 17h45 (GMT-3)

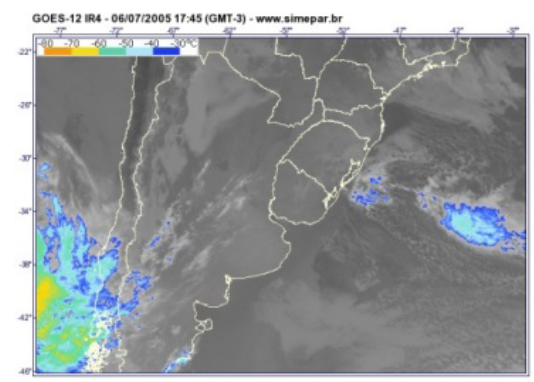

(c) 07/07 às 10h09 (GMT-3)

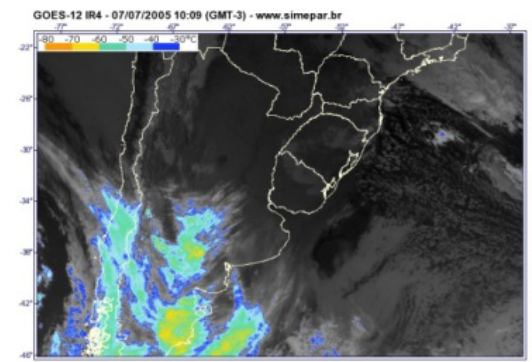

(b) 06/07 às $23 \mathrm{~h} 45$ (GMT-3)

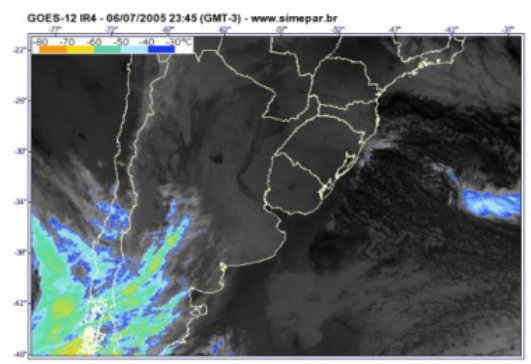

(d) 07/07 às $20 h 45$ (GMT-3)

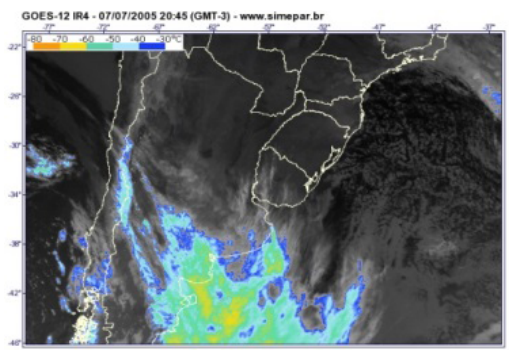

Figura 3 - Imagens Orbitais do Satélite GOES-12 (06 e 07 de julho de 2005) Fonte: SIMEPAR (Instituto Tecnológico do Paraná).

Em 20/08/2006 (Figura 4a, 4b, 4c e 4d), Guarapuava teve a temperatura mínima de $1,0^{\circ} \mathrm{C}$; Palmas $-0,4^{\circ} \mathrm{C}$ e Irati $3,5^{\circ} \mathrm{C}$. Nos dias anteriores, ocorreu a passagem de uma $\mathrm{mPa}$ que provocou queda nas temperaturas, porém no dia 20/08 a mesma se dissipou. Mesmo assim, esse sistema causa declínio na temperatura em Palmas. Em 22/08/2006, Guarapuava teve temperatura mínima de $2,0^{\circ} \mathrm{C}$; Palmas $-0,4^{\circ} \mathrm{C}$ e Irati $-1,3^{\circ} \mathrm{C}$ com a chegada de uma nova $\mathrm{mPa}$, que avançou pelo setor leste e se enfraqueceu no contato com a Serra Geral, mas conseguiu afetar as temperaturas em Palmas e Irati.

Em 05/06/2007, Guarapuava teve temperatura negativa de $-0,8^{\circ} \mathrm{C}$; Palmas $1,4^{\circ} \mathrm{C}$ e Irati $1,2^{\circ} \mathrm{C}$. Em Guarapuava ocorreu temperatura negativa em virtude da $\mathrm{mPa}$ reforçada pela $\mathrm{mPp}$, provocando queda na temperatura a oeste da Serra da Esperança. A mPp raramente chega ao Brasil, mas quando chega, mesmo enfraquecida, pode gerar diminuição nas temperaturas mínimas, principalmente pela sua elevada densidade. 
(a) 19/08 às $17 \mathrm{~h} 45$ (GMT-3)

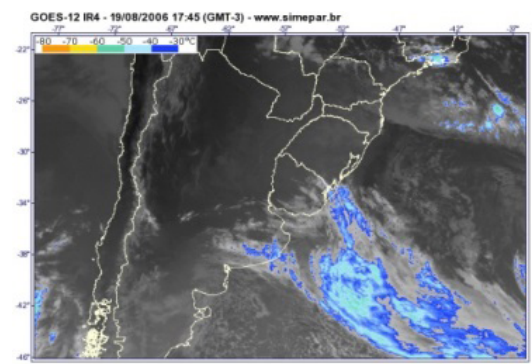

(c) 20/08 às $10 \mathrm{h09}$ (GMT-3)

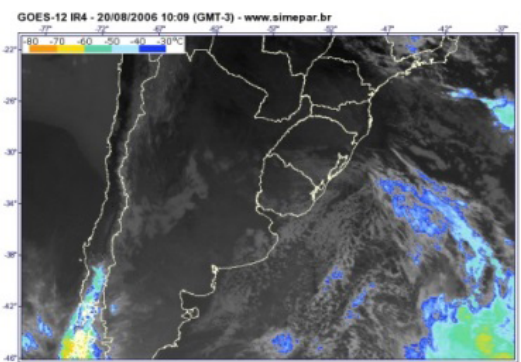

(b) 19/08 às $23 \mathrm{~h} 45$ (GMT-3)

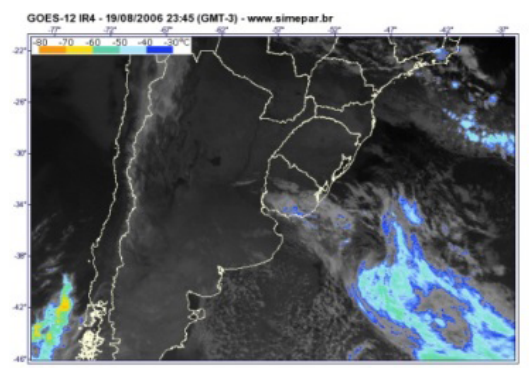

(d) $20 / 08$ às $20 \mathrm{~h} 45$ (GMT-3)

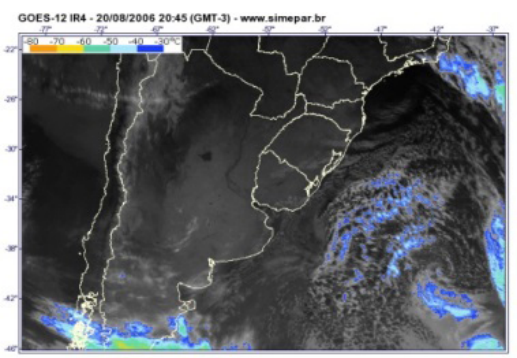

Figura 4 - Imagens Orbitais do Satélite GOES-12 (19 e 20 de agosto de 2006) Fonte: SIMEPAR (Instituto Tecnológico do Paraná).

No dia 30/06/2007, Guarapuava apresentou temperatura negativa de $-0,8^{\circ} \mathrm{C}$; Palmas também e Irati $1,8^{\circ} \mathrm{C}$. As temperaturas de Guarapuava e Palmas foram influenciadas pela $\mathrm{mPa}$ que provocou resfriamento significativo, o que é normal nessa época, mas em Irati não apresentou efeito algum.

Em 01/07/2007, Guarapuava teve temperatura mínima de-0, $4^{\circ} \mathrm{C}$; Palmas de $-1,4^{\circ} \mathrm{C}$ e Irati $2,4^{\circ} \mathrm{C}$. Neste mesmo dia, as temperaturas de Guarapuava e Palmas permaneceram baixas em virtude da mesma massa de ar, do dia anterior (mPa), continuar atuando e ter sido reforçada por outra frente fria que chegou na região.

No dia 24/07/2007, Guarapuava apresentou temperatura mínima de $2,0^{\circ} \mathrm{C}$ enquanto Palmas teve temperatura igual a $0^{\circ} \mathrm{C}$ e Irati $2,8^{\circ} \mathrm{C}$. As temperaturas de Palmas ficaram mais baixas em relação às outras áreas em virtude da passagem de uma mTc, bloqueando a ação de sistemas 
oriundos do sul. Nos dias 23 e 24, apesar da mTc continuar atuando, chega uma mPa mais intensa, provocando quedas nas temperaturas mínimas, principalmente em Palmas, por ficar mais ao Sul da região.

A temperatura mínima de Guarapuava no dia 28/07/2007 foi de $1,2^{\circ} \mathrm{C}$; Palmas $2,4^{\circ} \mathrm{C}$ e Irati teve temperatura negativa de $-0,2^{\circ} \mathrm{C}$. Com base nas imagens de satélite percebeu-se que neste dia uma mTc se deslocou sobre o Estado, impedindo que as temperaturas caíssem acentuadamente e, além disso, a mPp estava enfraquecida. Contudo, a cidade de Irati teve temperatura abaixo de zero, em virtude da localização (sopé da Serra da Esperança), concentrando todo o ar frio naquela região.

No dia 29/07/2007, Guarapuava obteve temperatura mínima de $2,8^{\circ} \mathrm{C}$, enquanto Palmas apresentou temperatura de -0,6 e Irati 2,6. Neste dia, atuou uma mPp que resfriou primeiramente a região de Palmas. Esta massa de ar ultrapassou a Cordilheira dos Andes e chegou ao Brasil principalmente pelo sul do Paraná.

Em 08/08/2007, a temperatura mínima de Guarapuava foi de $4,4^{\circ} \mathrm{C}$ Palmas $-0,2^{\circ} \mathrm{C}$ e Irati $3,0^{\circ} \mathrm{C}$. No dia $07 / 08$ cessa a ação de uma $\mathrm{mPa}$, mas no dia $08 / 08$ tem a chegada de uma nova $\mathrm{mPa}$, que provoca queda da temperatura em Palmas.

No dia 28/08/2007 (Figura 5a, 5b, 5c e 5d), Guarapuava teve temperatura mínima de $5,8^{\circ} \mathrm{C}$, enquanto Palmas teve $-0,8^{\circ} \mathrm{C}$ e Irati $5,7^{\circ} \mathrm{C}$. As temperaturas mais elevadas em Guarapuava e Irati são explicadas pela atuação da mTc, bloqueando a entrada de frentes frias. Entretanto, mais ao Sul, fica evidente que a massa de ar fria chega, atingindo cerca de $-40^{\circ} \mathrm{C}$ no topo das nuvens mais ao sul do Paraná (Palmas).

Em 2008, somente um dia (10/06/2008 - Figura 6a, 6b, 6c e 6d) teve temperaturas próximas de zero. Isso ocorreu em Palmas com $0,2^{\circ} \mathrm{C}$, enquanto Guarapuava apresentou $2,2^{\circ} \mathrm{C}$ e Irati $3,9^{\circ} \mathrm{C}$. Na maior parte do inverno ocorreram sucessivas passagens da mTc, como no dia 09 e no dia 10 de junho, deixando as temperaturas de Palmas mais baixas que as outras localidades.

No dia 04/06/2009, Irati apresentou temperatura negativa $-2,1^{\circ} \mathrm{C}$, enquanto Guarapuava foi de $1,0^{\circ} \mathrm{C}$ e Palmas $2,0^{\circ} \mathrm{C}$. A mPa influencia a temperatura de Irati, pois quando está chegando ao Paraná vai perdendo forças e se dissipa, atuando de forma mais intensa na região Sudeste, o que pode ter causado a queda mais acentuada da temperatura em Irati. 
(a) 27/08 às $20 \mathrm{~h} 45$ (GMT-3)

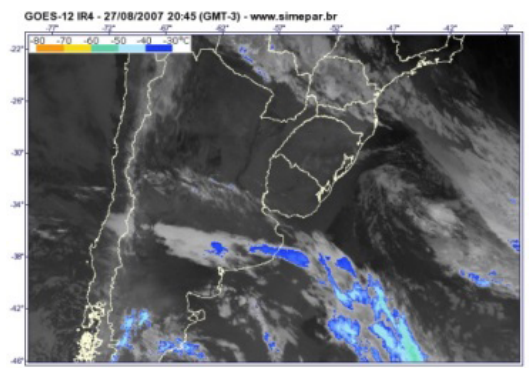

(c) 28/08 às 06h45 (GMT-3)

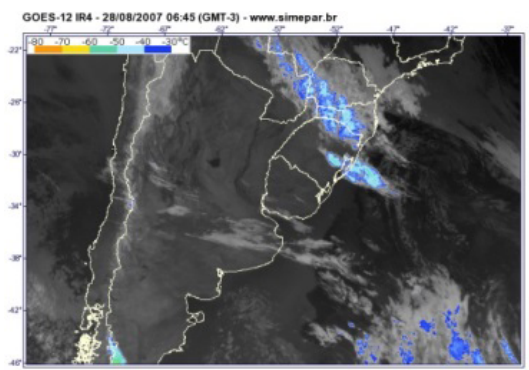

(b) 27/08 às $23 \mathrm{~h} 45$ (GMT-3)

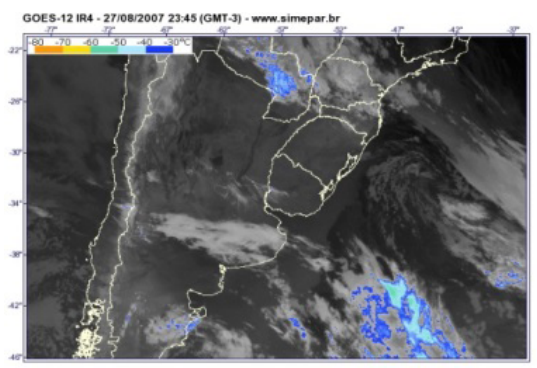

(d) 28/08 às $23 \mathrm{~h} 45$ (GMT-3)

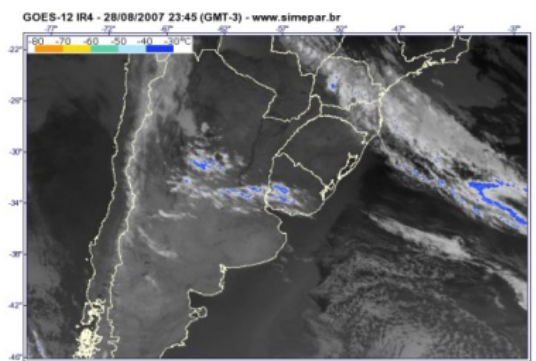

Figura 5 - Imagens Orbitais do Satélite GOES-12 (27 e 28 de agosto de 2007) Fonte: SIMEPAR (Instituto Tecnológico do Paraná).

Em 06/06/2009 (Figuras 7a; 7b; 7c e 7d), Guarapuava e Palmas apresentaram temperaturas mínimas de $-0,8^{\circ} \mathrm{C}$, enquanto Irati apresentou $3,4^{\circ} \mathrm{C}$. As temperaturas negativas foram influenciadas pela passagem da $\mathrm{mPa}$ no dia 05 e uma mPp, mesmo enfraquecida. Neste dia, com a chegada de outra $\mathrm{mPp}$ pelo ramo Oeste, ocorre a queda de temperatura primeiramente em Guarapuava e Palmas, chegando mais fraca em Irati.

No dia 01/07/2009, Palmas tem temperatura de $-1,2^{\circ} \mathrm{C}$, enquanto Guarapuava tem $2,8^{\circ} \mathrm{C}$ e Irati $3,3^{\circ} \mathrm{C}$. Nesse dia ocorre a passagem de uma mTc, impedindo que a frente fria avance mais, portanto somente em Palmas a temperatura fica negativa.

No mesmo sentido, no dia 24/07/2009, Palmas teve temperaturas de $-2^{\circ} \mathrm{C}$ e Irati de $-0,8^{\circ} \mathrm{C}$, enquanto Guarapuava teve sua mínima de $1,6^{\circ} \mathrm{C}$. Nessa mesma data a mTc se deslocou do Noroeste para o Sudeste do Paraná, impedindo quedas mais acentuadas em Guarapuava. Por sua vez, 
as temperaturas negativas de Palmas e Irati podem ser explicadas pela influência dos fatores climáticos (altitude e orografia). Ainda no mesmo mês, no dia 25 , Guarapuava teve temperatura de $-0,4^{\circ} \mathrm{C}$, Palmas de $-4,6^{\circ} \mathrm{C}$ e Irati $3,6^{\circ} \mathrm{C}$. Essa dinâmica foi influenciada pela atuação de uma mTc no dia anterior, mas a aproximação de uma mPa vence esse bloqueio e faz as temperaturas de Guarapuava e Palmas ficarem negativas.

(a) 09/06 às 06h39 (GMT-3)

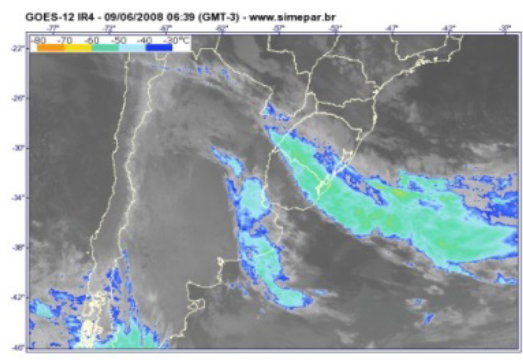

(c) 10/06 às 01h09 (GMT-3)

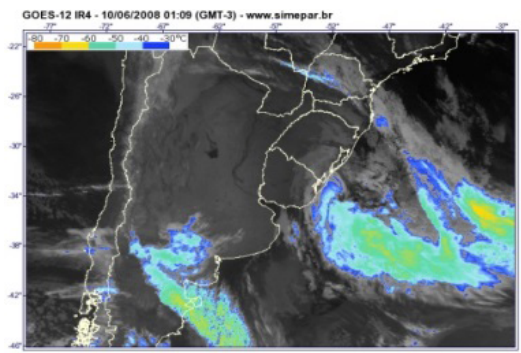

(b) 09/06 às 23h45 (GMT-3)

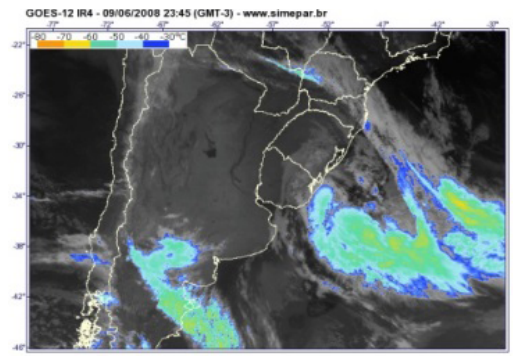

(d) 10/06 às 23h45 (GMT-3)

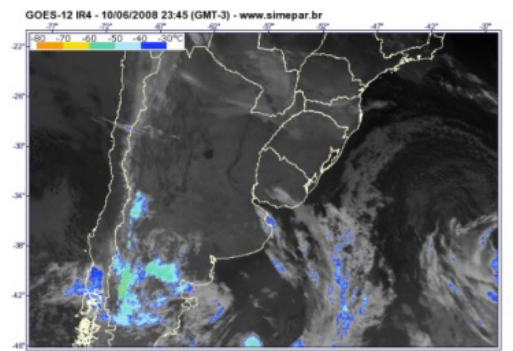

Figura 6 - Imagens Orbitais do Satélite GOES-12 (09 e 10 de junho de 2008) Fonte: SIMEPAR (Instituto Tecnológico do Paraná).

No dia 06 de junho de 2010, Guarapuava teve temperatura mínima de $-1^{\circ} \mathrm{C}$, Palmas $3^{\circ} \mathrm{C}$ e Irati $1,4^{\circ} \mathrm{C}$. No dia anterior ocorreu a passagem de uma $\mathrm{mTc}$, que pode ter impedido quedas mais acentuadas das temperaturas, portanto a mínima de Guarapuava pode ser explicada pela sua altitude mais elevada e não pela ação da $\mathrm{mPa}$. No dia 07 de junho, as temperaturas de Guarapuava permaneceram negativas $\left(-0,6^{\circ} \mathrm{C}\right)$, Palmas teve $2,6^{\circ} \mathrm{C}$ e Irati $2,5^{\circ} \mathrm{C}$. Em decorrência da influência do sistema que havia evoluído nos 
dias anteriores, a temperatura de Guarapuava permanece mais baixa em relação às outras áreas.

(a) 05/06 às $14 \mathrm{~h} 45$ (GMT-3)

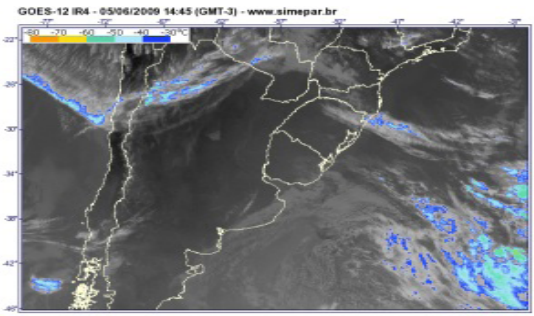

(c) $06 / 06$ às $14 \mathrm{~h} 45$ (GMT-3)

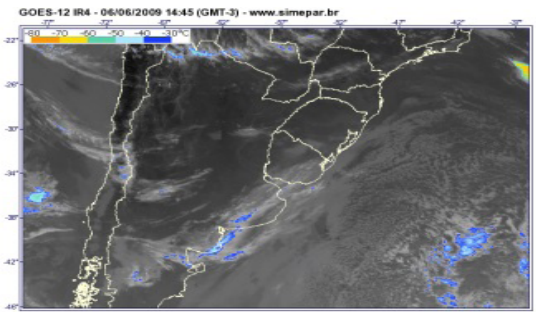

(b) 06/06 às $01 \mathrm{h09}$ (GMT-3)

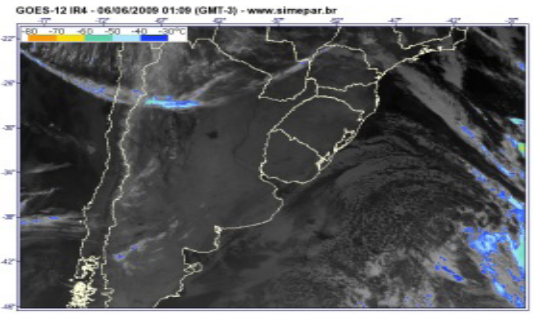

(d) 06/06 às $23 \mathrm{~h} 45$ (GMT-3)

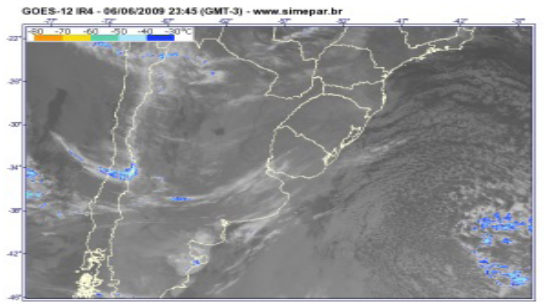

Figura 7 - Imagens Orbitais do Satélite GOES-12 (05 e 06 de junho de 2009) Fonte: SIMEPAR (Instituto Tecnológico do Paraná).

No dia 15/07/2010 (Figuras 8a, 8b, 8c e 8d), a temperatura mínima de Guarapuava foi de $4^{\circ} \mathrm{C}$; Palmas de $-0,4^{\circ} \mathrm{C}$ e Irati $2^{\circ} \mathrm{C}$. Nesse dia uma mTc atuou na região, evitando a queda de temperatura nas primeiras horas do dia, mas no final do período ela se dissipa e a mPa se intensifica, provocando queda instantânea da temperatura em Palmas, mais ao Sul.

Em 15/08/2010, Guarapuava teve temperatura mínima de $1,8^{\circ} \mathrm{C}$; Palmas de $-0,6^{\circ} \mathrm{C}$ e Irati $-0,9^{\circ} \mathrm{C}$. Nesse dia uma mTa atuou no continente, impedindo que as temperaturas decrescessem muito, mas mesmo assim, a mPa provocou pequeno declínio nas temperaturas em Palmas e Irati.

No dia 05/06/2011 (Figura 9a, 9b, 9c e 9d), Guarapuava teve temperatura mínima de $3,4^{\circ} \mathrm{C}$; Palmas $0^{\circ} \mathrm{C}$ e Irati $-1,6^{\circ} \mathrm{C}$. Essas temperaturas ocorreram num período em que houve a aproximação da $\mathrm{mPa}$ fortalecida 
pela mPp, provocando queda térmica em Palmas e Irati. Nota-se que essa massa de ar ainda não tinha chegado ao Paraná, mas a frente fria influenciou essa diminuição na temperatura.

(a) 15/07 às $05 \mathrm{~h} 45$ (GMT-3)

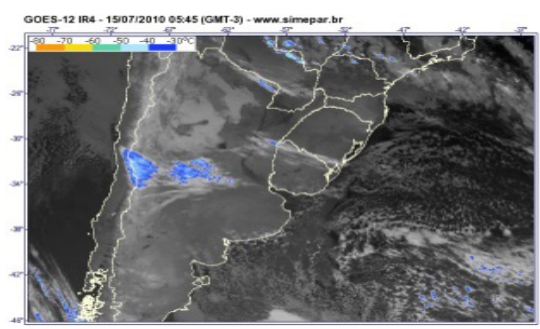

(c) 15/07 às 17 h45 (GMT-3)

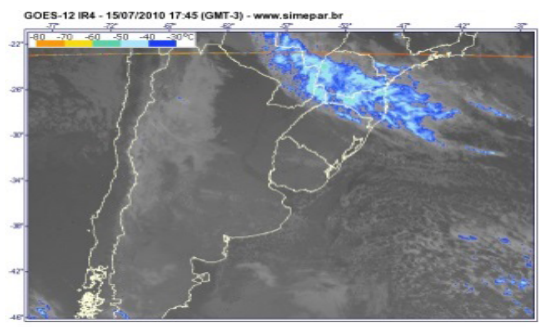

(b) 15/07 às $10 \mathrm{~h} 45$ (GMT-3)

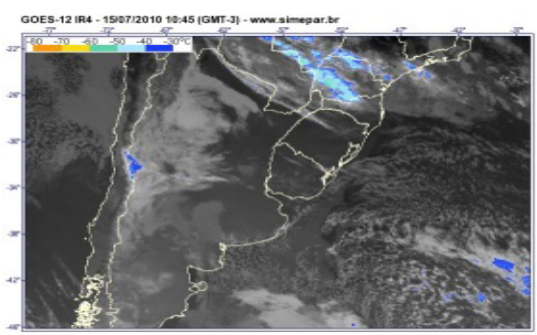

(d) $15 / 07$ às $23 \mathrm{~h} 45$ (GMT-3)

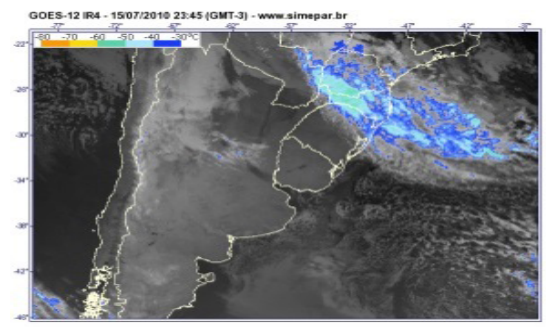

Figura 8 - Imagens Orbitais do Satélite GOES-12 (15 de julho de 2010)

Fonte: SIMEPAR (Instituto Tecnológico do Paraná).

No dia 11/06/2011, Guarapuava teve temperatura mínima de $4^{\circ} \mathrm{C}$; Palmas de $2,4^{\circ} \mathrm{C}$; enquanto Irati obteve $-1,6^{\circ} \mathrm{C}$. Percebe-se que a mPp se deslocou para o Sudeste do Paraná e provoca temperaturas negativas em Irati.

No dia 05/07/2011, Guarapuava teve temperatura mínima de $1,2^{\circ} \mathrm{C}$; Palmas $-0,2^{\circ} \mathrm{C}$ e Irati $0^{\circ} \mathrm{C}$. As temperaturas negativas de Palmas e Irati foram influenciadas pela $\mathrm{mPa}$, que passou pelo sudoeste do Paraná e acabou interferindo na dinâmica nesses municípios, com pouca atuação em Guarapuava, que sofria um bloqueio associado a ação da mTc. 
(a) 04/06 às 17h45 (GMT-3)

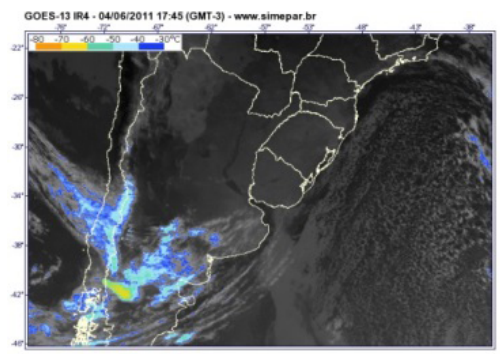

(c) 05/06 às 05h45 (GMT-3)

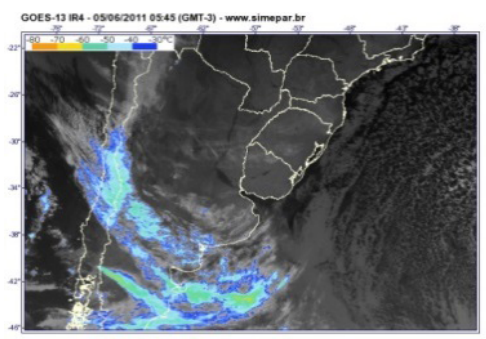

(b) 04/06 às $23 \mathrm{~h} 45$ (GMT-3)

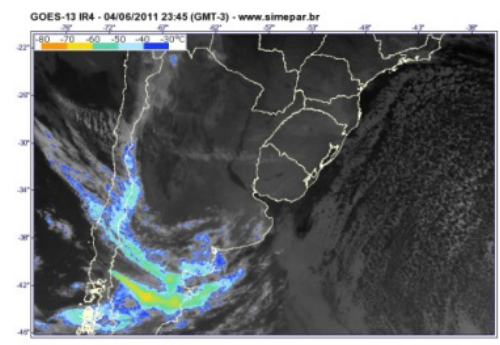

(d) $05 / 06$ às $20 \mathrm{~h} 45$ (GMT-3)

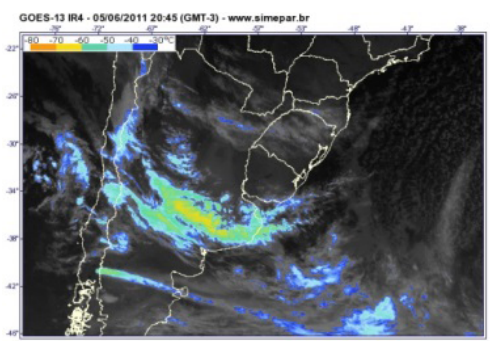

Figura 09 - Imagens Orbitais do Satélite GOES-12 (04 e 05 de junho de 2011) Fonte: SIMEPAR (Instituto Tecnológico do Paraná).

No dia 06 de julho, Guarapuava teve temperatura mínima de $3,2^{\circ} \mathrm{C}$; Palmas de $0^{\circ} \mathrm{C}$ e Irati $3,3^{\circ} \mathrm{C}$. Nesse dia, as temperaturas não ficaram tão baixas em virtude da ação da mTc. Contudo, no dia 07/07/2011, Guarapuava teve temperaturas negativas de $-0,4^{\circ} \mathrm{C}$; Palmas de $-2^{\circ} \mathrm{C}$ e Irati de $1,4^{\circ} \mathrm{C}$, com a atuação das massas de ar tropical continental nos dias antecedentes, mas substituída pela mPp, provocando queda das temperaturas, principalmente em Guarapuava e Palmas. Por fim, no dia 09/07, a temperatura mínima de Guarapuava foi de $3,2^{\circ} \mathrm{C}$; Palmas de 4,4 e Irati $0^{\circ} \mathrm{C}$, quando os sistemas atuantes nos dias anteriores se dissiparam totalmente.

No ano de 2012 foram selecionados três dias. Diante disso, no dia 08/07, Guarapuava teve temperatura mínima de $2,0^{\circ} \mathrm{C}$; Palmas $-0,6^{\circ} \mathrm{C}$; e Irati $3,1^{\circ} \mathrm{C}$. Nesse período, a atuação de uma mTc fez com que as temperaturas de Palmas fossem menores que Guarapuava e Irati. 
No dia 14/07/2012, a temperatura mínima de Guarapuava foi de $-0,2^{\circ} \mathrm{C}$, de Palmas $-0,6^{\circ} \mathrm{C}$ e Irati $1,7^{\circ} \mathrm{C}$. Nesse dia a mTc também impediu que Irati apresentasse temperaturas mais baixas, diferente das outras localidades. No dia 15/07/2012, a temperatura mínima de Guarapuava foi de $-0,2^{\circ} \mathrm{C}$, Palmas $1,6^{\circ} \mathrm{C}$ e Irati $2,2^{\circ} \mathrm{C}$, repetindo o processo do dia anterior.

No dia 20/07/2012 (Figura 10a, 10b, 10c e 10d),em Guarapuava, ocorreu a temperatura mínima de $-0,6^{\circ} \mathrm{C}$, Palmas $2,2^{\circ} \mathrm{C}$ e Irati $1,8^{\circ} \mathrm{C}$. Essa dinâmica foi fortemente influenciada pela ação de uma $\mathrm{mPa}$, reforçada pela $\mathrm{mPp}$, mas esse sistema se dissipou rapidamente no decorrer do período.

(a) 19/07 às $10 \mathrm{~h} 30$ (GMT-3)

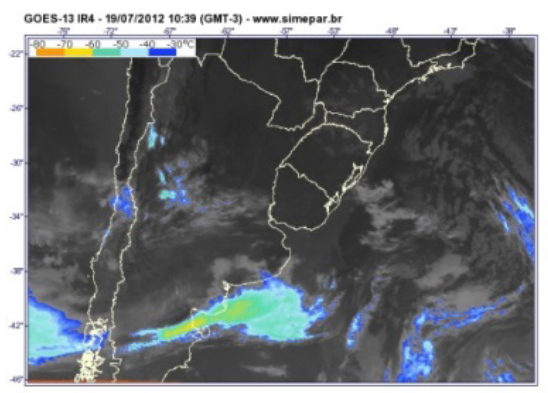

(c) 20/07 às $05 \mathrm{~h} 45$ (GMT-3)

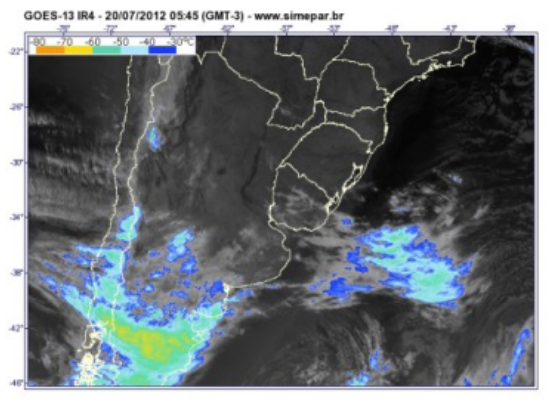

(b) 19/07 às $20 \mathrm{~h} 45$ (GMT-3)

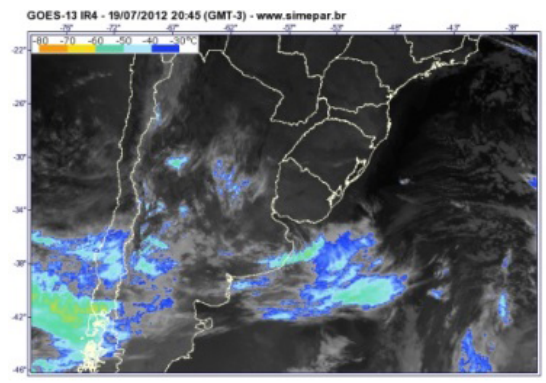

(d) 20/07 às 23h45 (GMT-3)

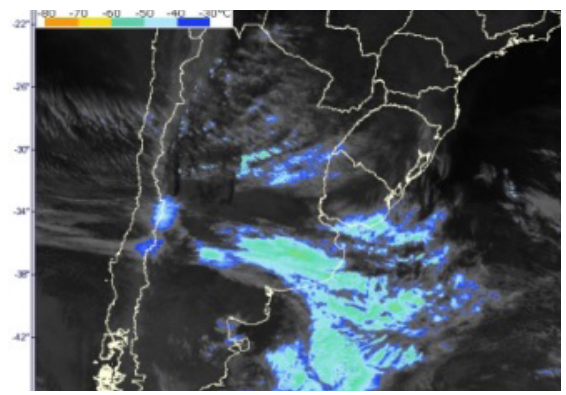

Figura 10 - Imagens Orbitais do Satélite GOES-12 (19 e 20 de julho de 2012) Fonte: SIMEPAR (Instituto Tecnológico do Paraná).

Todos os episódios analisados tiveram características muito parecidas com a ocorrência de ondas de frio. Contudo, como esse processo corresponde a tipos de tempo que representam variabilidades de grande escala espacial e curto prazo temporal, não foi possível confirmar tal 
hipótese. Isso demandaria uma investigação mais apurada sobre a gênese dos sistemas atmosféricos oriundos, tanto do sul, como do norte da América do Sul. Dessa forma, mesmo que alguns desses eventos tenham acentuado os dias típicos do inverno sulista, esse conceito não foi utilizado como método de análise no presente trabalho.

Outro aspecto a ser enfatizado é a atuação dos controles climáticos representados pela altitude/relevo da região de estudo. Enquanto Palmas e Guarapuava estão em altitudes próximas de $1100 \mathrm{~m}$ e na feição mais aplainada do relevo paranaense, denominada de terceiro planalto, Irati está localizada na transição do segundo para o terceiro planalto, com cotas próximas dos $800 \mathrm{~m}$. Essa configuração define feições geomorfológicas distintas, principalmente ao se comparar Irati com as outras localidades, pois o relevo côncavo da sede do município, onde se encontra a estação meteorológica do INMET, exerce papel preponderante na diferenciação dos climas locais (ANDRADE, 2010).

Esses resultados permitem uma associação marcante com o relevo local e regional. Nesse sentido, deve ser enfatizado que o município de Irati está localizado no segundo planalto paranaense, esculpido por rochas Paleozoicas e com estruturas monoclinais, sub-horizontais, mergulhado para oeste. Seus limites estão entre a escarpa Devoniana a leste, com altitudes médias entre 11001200 metros e a oeste com a escarpa de arenito-basáltico, onde suas altitudes variam entre 350 e 1200 metros. Por sua vez, os municípios de Guarapuava e Palmas estão situados no terceiro planalto paranaense, o qual corresponde ao grande derrame Mesozoico de rochas eruptivas básicas, mas também associado às rochas areníticas com relevos planálticos inclinados de oeste para noroeste, e suas altitudes médias de variam entre 1100 e 1250 metros na Serra da Esperança (Santos et al., 2006).

\section{Considerações Finais}

Todos os resultados obtidos permitem deduzir que a mPa (Massa Polar Atlântica), a mTc (Massa Tropical Continental), a mTa (Massa Tropical Atlântica) e a mPp (Massa Polar Pacifica), conjuntamente, atuam nas regiões Sul e Centro-Sul do Paraná durante o inverno austral. Não existe a ação só dos sistemas polares no período de mais frio na região, o que ficou comprovado pela identificação de sistemas tropicais atuando em vários dias do período analisado. 
Esse processo influencia de forma diferente as alternâncias térmicas em escala local, pois as temperaturas negativas mais significativas sempre são causadas pela ação das massas polares, mas isso não ocorre igualmente para as localidades investigadas. Normalmente, os municípios de Palmas (mais ao sul) e Irati (mais a leste) são dependentes desses sistemas, mas Guarapuava (mais a oeste) nem sempre tem suas temperaturas mínimas associadas à ação das massas polares, mas também ao efeito da altitude.

Os sistemas mais tropicalizados, como a Massa Equatorial, não exercem influência significativa no inverno da Região Sul Paranaense. Contudo, a mTa e a mTc, que também se originam nos trópicos, definem um eficiente bloqueio aos sistemas polares e isso é mais facilmente percebido em Guarapuava e Irati. Apesar disso, Irati, por estar numa área de relevo côncavo, concentra ar mais frio nas primeiras horas da manhã, propiciando temperaturas mínimas menos dependentes das massas polares, pois sua dinâmica termal está mais associada ao efeito catabático dos ventos locais.

Por outro lado, Guarapuava tem a presença mais constante da mTa e mTc, impedindo quedas mais abruptas das temperaturas de inverno. $\mathrm{O}$ fluxo dos ventos oriundos do quadrante Sul não encontra muita resistência do relevo mais aplainado até chegar em Guarapuava, definindo temperaturas mínimas dissociadas da escala secundária do clima (massas de ar) e mais dependentes dos fatores geográficos locais (relevo e uso da terra).

Essa mesma configuração geomorfológica também funciona no sentido leste/oeste, tendo a escarpa da Serra da Esperança como divisor de condições climáticas um pouco distintas, pelo menos na escala diária.

\section{Agradecimentos}

Os autores agradecem à Fundação Araucária - Apoio ao Desenvolvimento Científico e Tecnológico do Paraná, pela concessão de Bolsa de Estudos para o desenvolvimento de pesquisa que propiciou dados para o trabalho. Agradecem também ao SIMEPAR, ao INMET e ao IAPAR pela cessão de imagens de satélite e dados de temperatura do ar.

\section{Nota}

${ }^{1}$ Os dados destacados em amarelo se referem aos dias e locais em que as temperaturas mínimas absolutas foram menores que zero (negativas). 


\section{Referências}

ANDRADE, A. R. Articulações entre o clima urbano e o clima regional: uma abordagem a partir da análise de Irati e Guarapuava/PR. 2010. Tese (Doutorado em Geografia) - Universidade Federal do Paraná, Curitiba, 2010.

AYOADE, J. O. Introdução à Climatologia para os Trópicos. 4. ed., Rio de Janeiro: Bertrand do Brasil, 1996.

CAVIGLIONE, J. H.; KIIHL, L. R. B.; CARAMORI, P. H.; OLIVEIRA, D. Cartas climáticas do Paraná. Londrina: IAPAR, 2000. CD.

COSTA, E.R. A onda de frio de junho de 2012 no Rio Grande do Sul: gênese, duração e temperaturas mínimas registradas. Revista Geografia, Ensino e pesquisa, v.17, n.2 maio/ago., 2013.

IAPAR, Instituto Agronômico do Paraná. Dados de temperatura do ar. 2014

IPARDES. Instituto Paranaense de Desenvolvimento Econômico e Social. Cadernos estatísticos. Dezembro 2013. Disponível em: <http://www.ipardes.gov. br/index.php?pg_conteudo $=1 \&$ cod_conteudo $=30>$. Acesso em: out. 2013.

INMET (Instituto Nacional de Meteorologia). Plataforma de estações de Dados. Disponível em:<http://www.inmet.gov.br/portal/index.php?r=bdmep/bdmep $>$. Acesso em: set. 2013.

SANTOS, L. J C.; OKA-FIORI, C.; CANALI, N. E.; FIORI, A. P.; SILVEIRA, C. T.; SILVA, J. M. F.; e ROSS, J. L. S. Mapeamento Geomorfológico do Estado do Paraná. Revista Brasileira de Geomorfologia, ano 7, n. 2, 2006.

SIMEPAR, Instituto tecnológico. Imagens orbitais satélite Goes-13, 2014.

VAREJÃO-SILVA, M. A. Meteorologia e Climatologia. Brasília: MA-INMET, 2001.

THOMAZ, E. L. e VESTENA, L. R. Aspectos climáticos de Guarapuava-PR. Guarapuava: Unicentro, 2003.

Claudiane da Costa - Possui Graduação em Geografia pela Universidade Estadual do Centro-0este. Atualmente é Mestranda em Geografia pela mesma universidade.

Aparecido Ribeiro de Andrade - Possui Graduação e Mestrado em Geografia pela Universidade Estadual de Maringá. Possui Doutorado em Geografia pela Universidade Federal do Paraná. Atualmente é Professor Adjunto da Universidade Estadual do Centro-Oeste.

Recebido para publicação em 20 de setembro de 2015 Aceito para publicação em 18 de outubro de 2015 